\title{
Sistem Informasi Akuntansi Pengelolaan Keuangan pada Davia Laundry Kubu Raya
}

\author{
Alazmi $^{1}$, Niswatul Ummi ${ }^{2}$, Lisnawanty ${ }^{3}$, Ardiyansyah ${ }^{4}$
}

\section{Info Artikel}

Diterima Desember, 18, 2020

Revisi Januari, 18, 2021

Terbit Maret, 30, 2021

\section{Keywords:}

Sistem Informasi Akuntansi

Keuangan

Davia Laundry

Model Air Terjun

Standar Akuntansi Keuangan

\begin{abstract}
Davia Laundry is a laundry service provider. The system used in Davia Laundry still uses a manual system in the data recording process, this allows data recording errors. If there is an error, it will result in loss and customer trust will be lost. In addition, this manual system takes longer in the process of receiving goods until they are returned to consumers. Therefore, this study discusses financial management accounting information systems that use the waterfall model as a software development model which consists of software requirements analysis, design, programming and testing. Data collection techniques used consisted of observation, interviews and literature study. This system provides facilities for two levels of access, namely Admin and Owner. Admin can manage account data, customer data, package data, service and tariff data, order transactions, payment transactions, expense transactions, access income reports, expense reports, general journals, ledgers, trial balances, income statements and reports of changes in capital and balance sheet. Owners can manage user data, access income reports, expense reports, general journals, ledgers, trial balances, income statements and reports on changes in capital and balance sheets. This system is made with the programming language PHP and MySQL as a database application. The system that has been created is expected to help improve work, especially in financial management, which can produce financial reports in accordance with financial accounting standards and on time so that they can be used as a basis for decision making.
\end{abstract}

\section{Identitas Penulis:}

Alazmi $^{1}$, Niswatul Ummi ${ }^{2}$, Lisnawanty ${ }^{3}$, Ardiyansyah $^{4}$

PSistem Informasi Akuntansi Kampus Kota Pontianak, Universitas Bina Sarana Informatika

Jalan Abdurahman Saleh, No. 18A, Pontianak

Email: alazmi2468@gmail.com ${ }^{1}$, $\underline{\text { umminiswatul@gmail.com }}^{2}$, lisnawanty.1sy@ @si.ac.id ${ }^{\mathbf{3}}$, ardiyansyah.arq@bsi.ac.id $^{4}$

\section{PENDAHULUAN}

Saat ini usaha jasa laundry banyak sekali ditemui di setiap sudut kota bahkan sampai masuk desa. Jasa yang ditawarkan sangat beragam, ada yang menggunakan jasa laundry yang dihitung per item tapi dengan biaya yang lebih mahal. Ada juga dengan penghitungan per kg, sehingga biaya menjadi lebih murah dan bisa menggunakan jasa antar jemput barang. Berbagai penawaran menarik diberikan oleh jasa usaha laundry untuk menarik konsumen. Bisnis usaha laundry adalah bisnis jasa kepercayaan. Davia Laundry merupakan salah satu penyedia jasa pencucian pakaian. Sistem yang digunakan dalam Davia Laundry masih menggunakan sistem manual dalam proses pencatatan data, hal ini memungkinkan kesalahan pencatatan data. Jika terjadi kekeliruan maka akan mengakibatkan kerugian dan kepercayaan pelanggan akan hilang. Selain itu, sistem yang manual ini membutuhkan waktu yang lebih lama dalam proses penerimaan barang sampai pengembalian barang ke konsumen. Maka dari itu penelitian ini membahas mengenai Sistem Informasi Akuntansi Pengelolaan Keuangan Davia Laundry Kubu Raya.

\section{METODE}

Metode penelitian menurut Sugiyono dalam merupakan cara ilmiah dalam mendapatkan data yang valid, dengan tujuan dapat ditemukan, dikembangkan dan dibuktikan, suatu pengetahuan tertentu sehingga pada gilirannya dapat digunakan untuk memahami, memecahkan, dan mengantisipasi masalah[1]. 


\subsection{Metode Pengembangan Software}

Menurut Rosa dan Shalahuddin dalam menjelaskan bahwa model SDLC air terjun (waterfall) sering juga disebut model sekuensial linier (sequential linear) atau alur hidup klasik (classic life cycle)[2]. Model air terjun menyediakan pendekatan alur hidup perangkat lunak secara sekuensial atau terurut dimulai dari analisis, desain, pengkodean, pengujian dan tahap pendukung (support).

Berikut adalah gambar model waterfall sebagai metode pengembangan software.

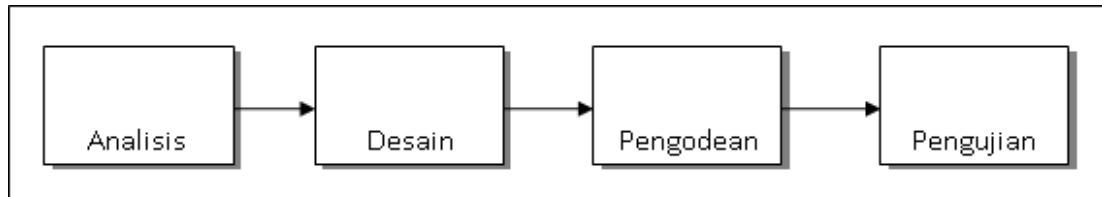

Sumber : (Rosa \& Shalahuddin, 2015)[3]

\section{Gambar 1. Model Waterfall}

Tahap-tahap waterfall model sebagai berikut[3]:

1. Analisis kebutuhan perangkat lunak

Proses pengumpulan kebutuhan dilakukan secara intensif untuk menspesifikasikan kebutuhan perangkat lunak agar dapat dipahami perangkat lunak yang dibutuhkan oleh user.

2. Desain

Desain perangkat lunak adalah proses multi langkah yang fokus pada desain pembuatan program perangkat lunak termasuk struktur data, arsitektur perangkat lunak, representasi antarmuka, dan prosedur pengodean. Dimana penulis mendesain keseluruhan dari program yang akan dibuat.

3. Pembuatan kode program

Desain harus ditranslasikan kedalam program perangkat lunak. Hasil dari tahap ini adalah program komputer sesuai dengan desain yang telah dibuat pada tahap desain. Penulis melakukan pengkodingan pada tahap ini.

4. Pengujian

Pengujian fokus pada perangkat lunak secara dari segi lojik dan fungsional dan memastikan bahwa semua bagian sudah diuji. Hal ini dilakukan untuk meminimalisir kesalahan (error) dan memastikan keluaran yang dihasilkan sesuai dengan yang diinginkan. Dimana tahap ini penulis melakukan pengujian menggunakan blackbox testing.

\subsection{Teknik Pengumpulan Data}

Teknik pengumpulan data yang digunakan dalam penelitian ini sebagai berikut.

1. Pengamatan (Observation)

Penulis melakukan observasi atau pengamatan secara langsung ke lokasi penelitian yaitu melihat langsung proses perhitungan pengelolaan keuangan pada Davia Laundry yang beralamat diKampung Arang, gang Patria I, nomor A24, Kabupaten Kubu Raya.

2. Wawancara (Interview)

Penulis melakukan suatu metode tanya jawab kepada Ibu Beti selaku pemilik Davia Laundry mengenai kegiatan dan permasalahan yang berhubungan dengan perusahaan khususnya kegiatan pengelolaan keuangan pada Davia Laundry.

3. Studi pustaka

Studi pustaka dilakukan dengan mengumpulkan beberapa referensi yang bersumber dari buku, jurnal, maupun referensi lainnya di internet.

\section{HASIL}

3.1. Analisis Kebutuhan Perangkat Lunak

Tahapan analisis ini menguraikan tentang kebutuhan pengguna atau spesifikasi kebutuhan yang diperlukan dari sistem pengelolaan pada Davia Laundry.

\section{Tabel 1. Analisis Kebutuhan Pengguna}

A1 Skenario Kebutuhan Bagian Admin

a. Login

A2 Skenario Kebutuhan Pemilik

a. Login


Vol. 02, No. 01, Maret 2021, pp. 01 10

ISSN: 2721-7523
b. Mengelola data rekening akun
b. Mengelola data pengguna
c. Mengelola data pelanggan
c. Mengakses laporan penerimaan
d. Mengelola data paket
d. Mengakses laporan pengeluaran
e. Mengelola service dan tarif
e. Mengakses laporan jurnal umum
f. Mengelola transaksi order
f. Mengakses buku besar
g. Mengelola transaksi pembayaran
g. Mengakses neraca saldo
h. Mengelola transaksi pengeluaran
h. Mengakses laporan laba rugi
i. Mengakses laporan penerimaan
i. Mengakses laporan perubahan modal
j. Mengakses laporan pengeluaran
j. Mengakses neraca
k. Mengakses jurnal umum
k. Logout
1. Mengakses buku besar
m. Mengakses neraca saldo
n. Mengakses laporan laba rugi
o. Mengakses laporan perubahan modal
p. Mengakses neraca
q. Logout

Sumber: Hasil Penelitian (2020)

\subsection{Desain}

1. Use Case Diagram

Gambar 2 berikut ini merupakan rancangan use case diagram pada sistem informasi akuntansi pengelolaan keuangan Davia Laundry. 
Vol. 02, No. 01, Maret 2021, pp. 01 10

ISSN: 2721-7523

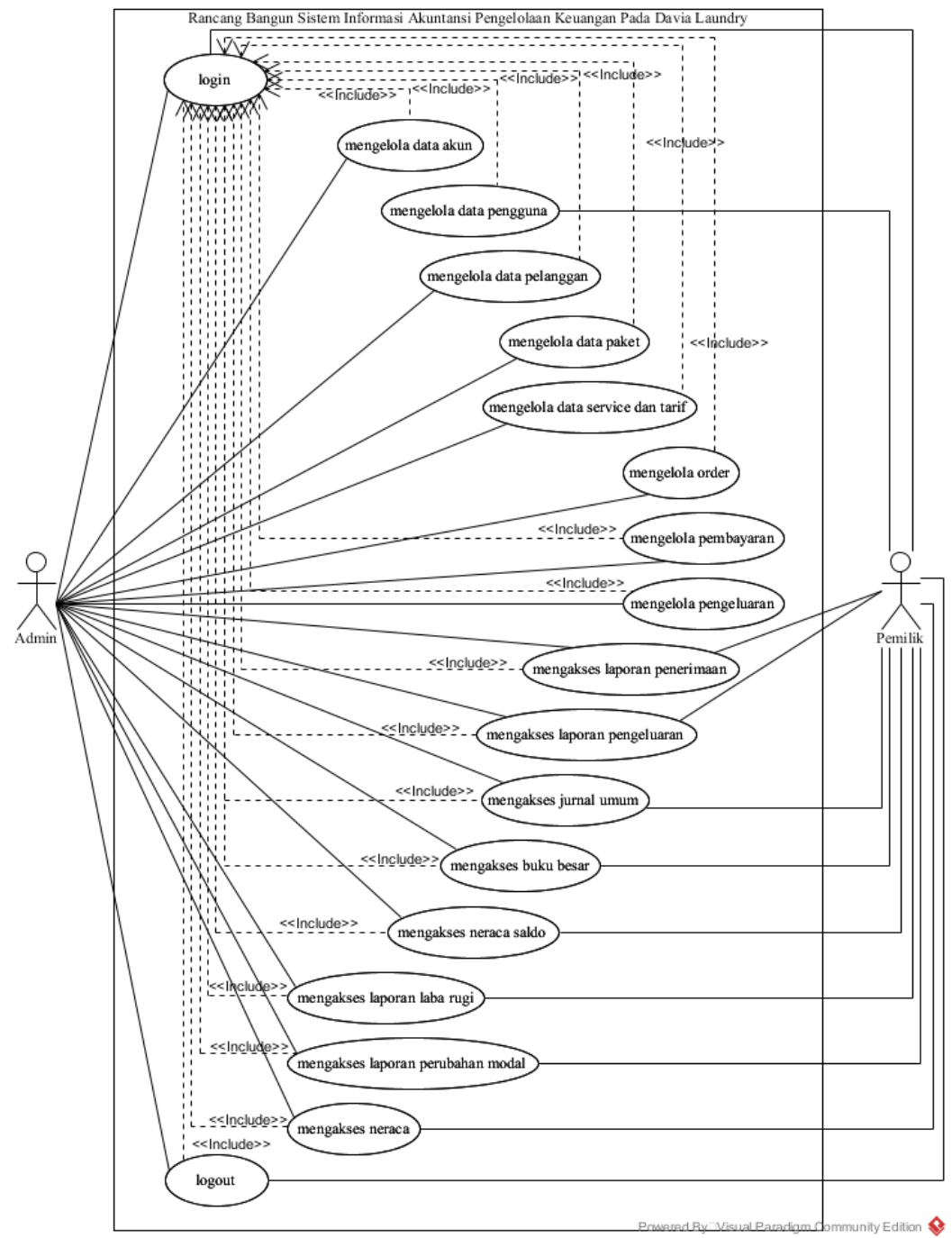

Sumber: Hasil Penelitian (2020)

Gambar 2. Rancangan Use Case Diagram 
2. Desain Basis Data

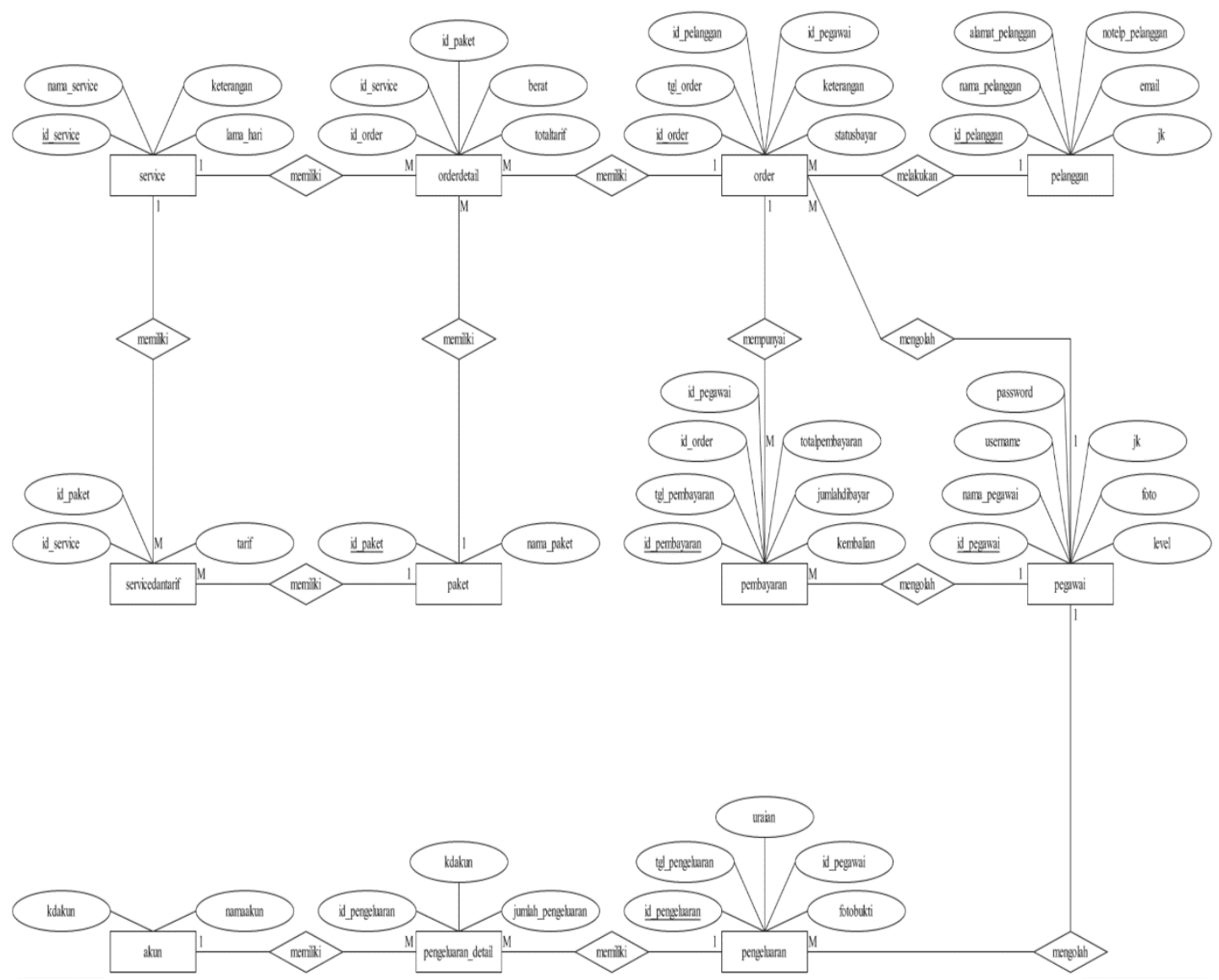

Sumber: Hasil Penelitian (2020)

Gambar 3. Entity Relationship Diagram

\subsection{Pembuatan Kode Program}

Dalam pembuatan kode program, sistem informasi akuntansi ini dirancang dengan menggunakan framework codeigniter, bahasa pemrograman yang digunakan php, Xampp v3.2.2 sebagai web server, dan Visual Studio Code sebagai web editor.

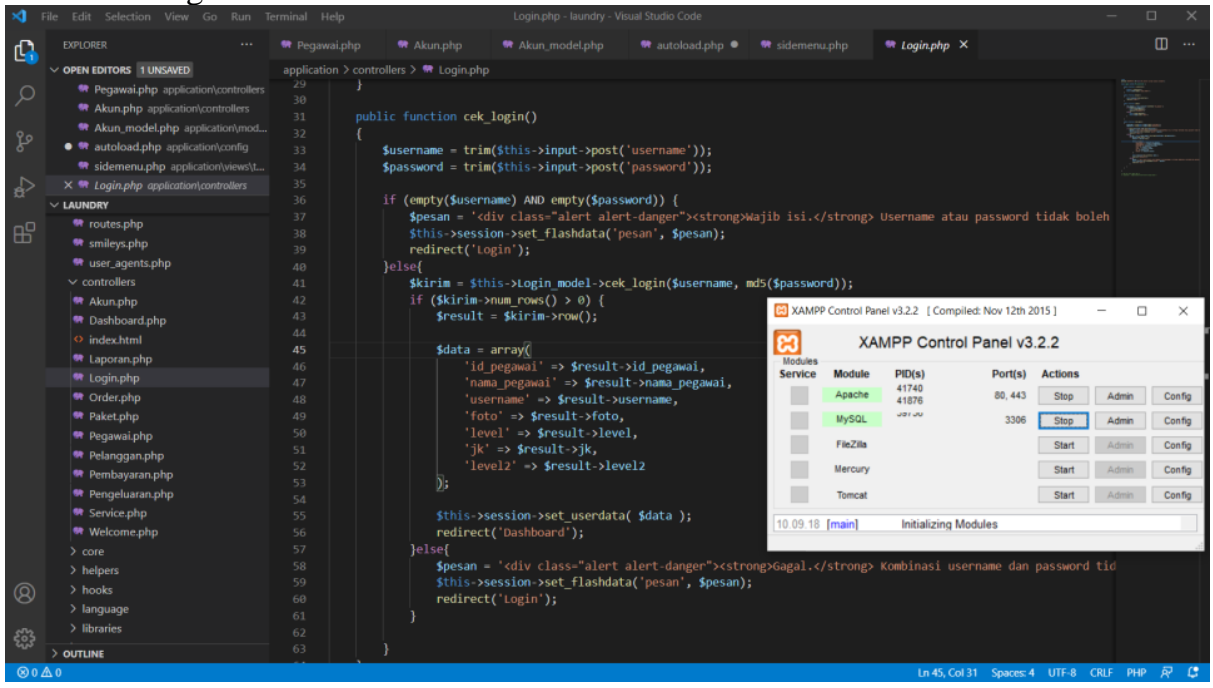

Sumber: Hasil Penelitian (2020)

Gambar 4. Pembuatan Kode Program 
Hasil rancangan user interface atau antarmuka dari sistem pengelolaan berbasis web pada Davia Laundry ini menyediakan fasilitas kepada dua (2) level pengguna, yaitu Admin dan Pemilik. Admin harus mengisi username dan password agar dapat mengakses sistem pengelolaan sesuai dengan level aksesnya, sebagaimana terlihat pada Gambar 3 berikut ini.

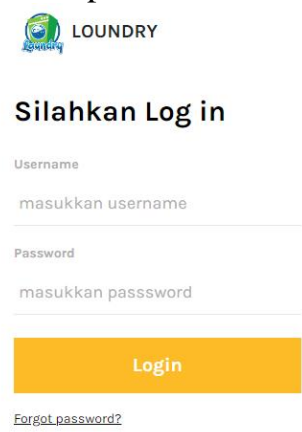

Sumber: Hasil Penelitian (2020)

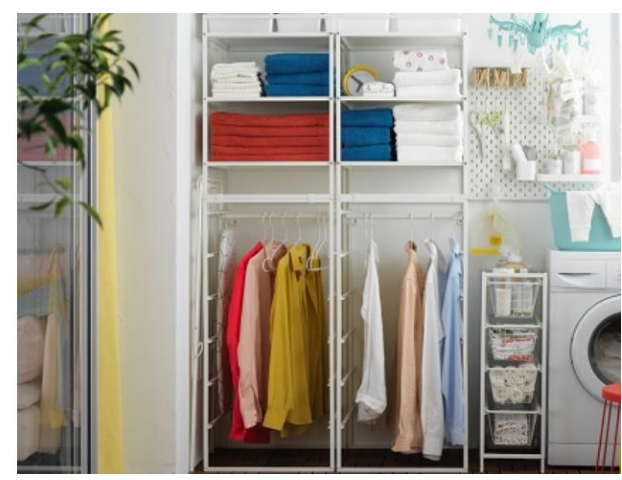

Gambar 5. Halaman Login

Setelah berhasil melakukan login, Admin dapat mengelola data akun, data pelanggan, data paket, data service dan tarif, transaksi order, transaksi pembayaran, transaksi pengeluaran dan mengakses laporan keuangan apabila telah melewati proses login, sebagaimana terlihatn pada Gambar 4 berikut ini.

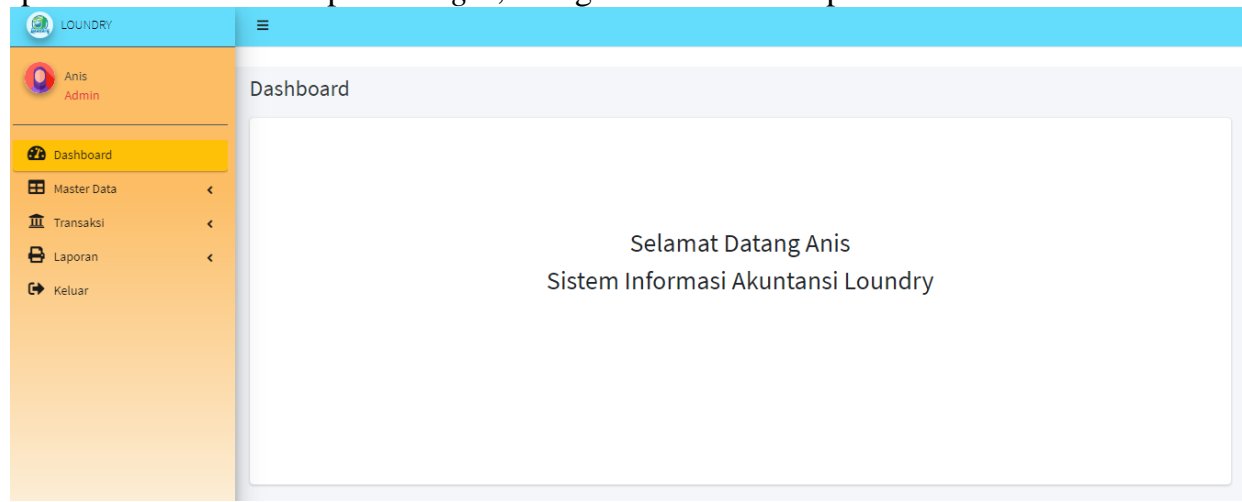

Sumber: Hasil Penelitian (2020)

\section{Gambar 6. Halaman Menu (Admin)}

Sementara, Pemilik dapat mengelola data pengguna dan mengakses laporan, sebagaimana terlihat pada Gambar 5 berikut ini.

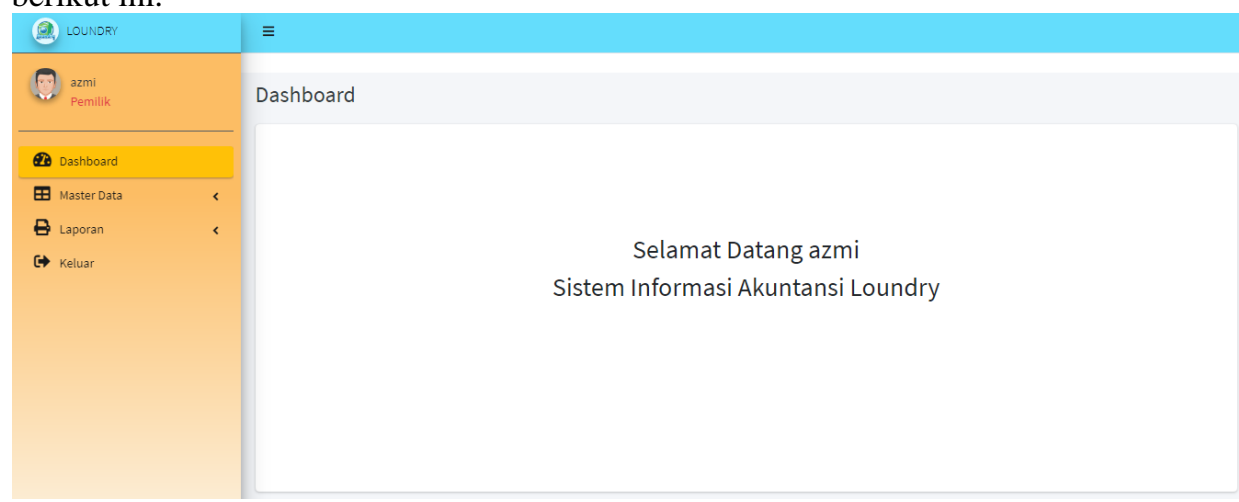

Sumber: Hasil Penelitian (2020)

\section{Gambar 7. Halaman Menu (Pemilik)}

Pada sistem informasi akuntansi ini, terdapat data master dan data transaksi yang akan diolah oleh Admin atau Pemilik. Data master tersebut, antara lain data akun, pelanggan, paket, service dan tarif, serta 
pengguna. Masing-masing halaman akan menampilkan list data yang pernah diolah, kemudian memudahkan bagi pengguna (baik Admin atau Pemilik) untuk menambah, mengubah, atau menghapus data, sebagaimana terlihat pada Gambar berikut.

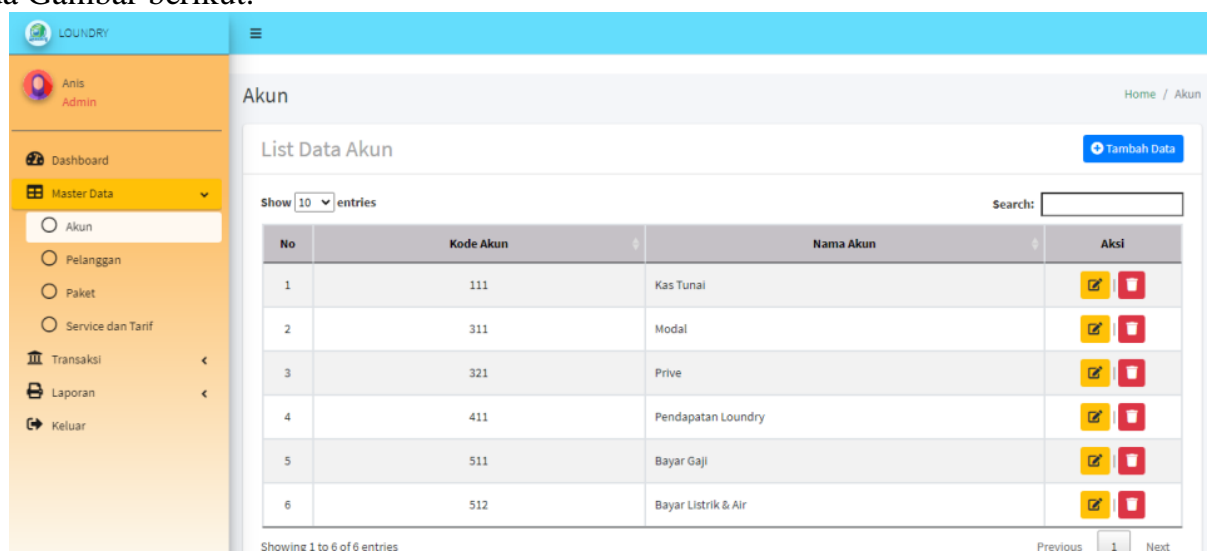

Sumber: Hasil Penelitian (2020)

\section{Gambar 8. Tampilan Halaman Akun}

Selain data master, data transaksi yang diolah data sistem ini, antara lain transaksi order, pembayaran, dan pengeluaran. Beberapa luaran yang dihasilkan sistem informasi akuntansi pengelolaan keuangan pada Davia Laundry, antara lain laporan penerimaan, laporan pengeluaran, jurnal umum, buku besar, neraca saldo, laporan laba rugi, laporan perubahan modal, dan neraca. Data yang akan tampil dalam laporan dicari berdasarkan periode waktu, sebagaimana contoh yang terlihat pada gambar berikut ini.

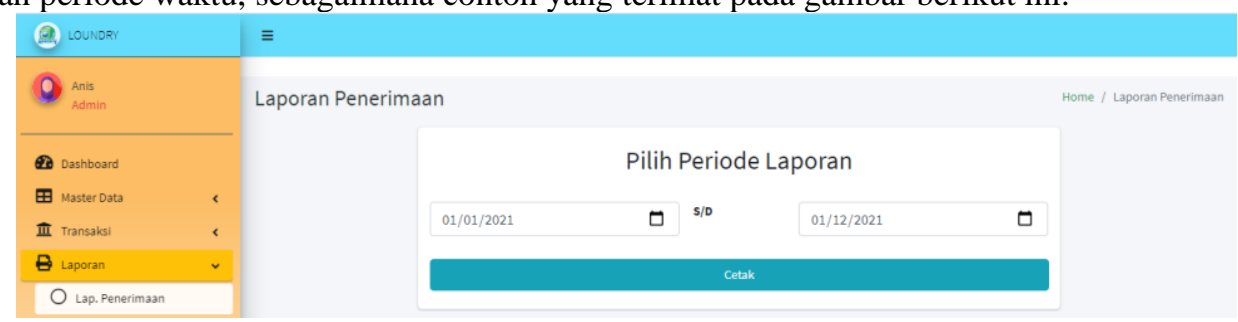

Sumber: Hasil Penelitian (2020)

Gambar 9. Tampilan Luaran Laporan Penerimaan Kas

\section{DAVIA LAUNDRY}

Jalan Adi Sucipto Gg. Patria 1, No. 24 Kubu Raya $\mid 082150404400$

\section{LAPORAN PENERIMAAN}

PERIODE 01 JANUARI 2021 S/D 12 JANUARI 2021

\begin{tabular}{|c|c|l|r|r|r|}
\hline NO & TANGGAL & \multicolumn{1}{|c|}{ KETERANGAN } & \multicolumn{1}{c|}{ BERAT } & \multicolumn{1}{c|}{ TARIF } & \multicolumn{1}{c|}{ JUMLAH } \\
\hline 1 & $20-01-2021$ & Pembayaran An. Susi & & & 191,000 \\
\hline & & One Day Care/ Cucian & 3.00 & 5,000 & \\
\hline & & One Day Care/ Cuci \& Setrika & 22.00 & 8,000 & \\
\hline 2 & $20-01-2021$ & Pembayaran An. Iqbal & & & 42,000 \\
\hline & & Regular/ Cucian & 14.00 & 3,000 & \\
\hline \multicolumn{4}{|r|}{ TOTAL } & $\mathbf{2 3 3 , 0 0 0}$ \\
\hline
\end{tabular}

Sumber: Hasil Penelitian (2020)

Gambar 10. Tampilan Cetakan Laporan Penerimaan Kas 


\subsection{Pengujian}

Pengujian dilakukan untuk menguji kelayakan fungsional dari sistem pengelolaan berbasis web pada

Davia Laundry. Teknik yang digunakan untuk pengujian ini adalah menggunakan teknik black box testing.

1. Pengujian browser

Pengujian kelayakan browser ini berfungsi untuk memastikan keadaan tampilan aplikasi apabila diakses menggunakan browser yang berbeda. Hasil pengujian browser dapat dilihat pada tabel berikut.

Tabel 2. Black Box Testing Browser

\begin{tabular}{|c|c|c|c|c|c|}
\hline No. & $\begin{array}{l}\text { Skenario } \\
\text { pengujian }\end{array}$ & Test case & $\begin{array}{l}\text { Hasil yang } \\
\text { diharapkan }\end{array}$ & $\begin{array}{c}\text { Hasil } \\
\text { pengujian }\end{array}$ & Kesimpulan \\
\hline 1. & $\begin{array}{c}\text { Buka dengan } \\
\text { Google Chrome }\end{array}$ & $\begin{array}{c}\text { Google Chrome } \\
\text { (terbuka) }\end{array}$ & $\begin{array}{c}\text { Aplikasi dapat } \\
\text { diakses dan tampilan } \\
\text { sesuai }\end{array}$ & Sesuai harapan & Valid \\
\hline 2. & $\begin{array}{l}\text { Buka dengan } \\
\text { Mozila Firefox }\end{array}$ & $\begin{array}{l}\text { Mozila Firefox } \\
\quad \text { (terbuka) }\end{array}$ & $\begin{array}{c}\text { Aplikasi dapat } \\
\text { diakses dan tampilan } \\
\text { sesuai }\end{array}$ & Sesuai harapan & Valid \\
\hline
\end{tabular}

Sumber: Hasil Penelitian (2020)

2. Pengujian login

Pengujian halaman login dilakukan untuk memastikan kolom-kolom pengisian dan pembatasan login apabila pengguna melakukan proses login Hasil pengujian login dapat dilihat pada tabel berikut.

Tabel 3. Black Box Testing Halaman Login

\begin{tabular}{|c|c|c|c|c|c|}
\hline No. & $\begin{array}{c}\text { Skenario } \\
\text { pengujian }\end{array}$ & Test case & $\begin{array}{c}\text { Hasil yang } \\
\text { diharapkan }\end{array}$ & $\begin{array}{c}\text { Hasil } \\
\text { pengujian }\end{array}$ & Kesimpulan \\
\hline 1. & $\begin{array}{l}\text { Jika salah satu } \\
\text { kolom } \\
\text { dikosongkan }\end{array}$ & $\begin{array}{l}\text { username: } \\
\text { (kosong) }\end{array}$ & $\begin{array}{l}\text { aplikasi menolak } \\
\text { akses dan } \\
\text { menampilkan pesan } \\
\text { "please fill out this } \\
\text { field" }\end{array}$ & Sesuai harapan & Valid \\
\hline 2. & $\begin{array}{c}\text { Kolom terisi } \\
\text { namun tidak } \\
\text { sesuai (username, } \\
\text { password dan } \\
\text { level akses tidak } \\
\text { sesuai) }\end{array}$ & $\begin{array}{l}\text { username: } \\
(55555) \\
\text { password: } \\
(55555)\end{array}$ & $\begin{array}{l}\text { aplikasi menolak } \\
\text { akses dan } \\
\text { menampilkan pesan } \\
\text { "username atau } \\
\text { password anda salah, } \\
\text { silahkan coba lagi” }\end{array}$ & $\begin{array}{l}\text { Tidak Sesuai } \\
\text { Harapn }\end{array}$ & Invalid \\
\hline 3 & $\begin{array}{l}\text { Kolom terisi dan } \\
\text { sesuai (username } \\
\text { dan password } \\
\text { sesuai) }\end{array}$ & $\begin{array}{l}\text { username: } \\
\text { (admin) } \\
\text { password: } \\
\text { (admin) }\end{array}$ & $\begin{array}{l}\text { Aplikasi menerima } \\
\text { akses dan membuka } \\
\text { halaman utama. }\end{array}$ & Sesuai Harapan & Valid \\
\hline
\end{tabular}

Sumber: Hasil Penelitian (2020)

3. Pengujian tambah data pengeluaran

Pengujian tambah data pengeluaran ini dilakukan untuk mengetahui kelayakan menu dari penambahan data pengeluaran. Hasil pengujian tambah data pengeluaran dapat dilihat pada tabel berikut.

Tabel 4. Black Box Testing Halaman Tambah Data Pengeluaran

\begin{tabular}{cccccc}
\hline No. & $\begin{array}{c}\text { Skenario } \\
\text { pengujian }\end{array}$ & Test case & $\begin{array}{c}\text { Hasil yang } \\
\text { diharapkan }\end{array}$ & $\begin{array}{c}\text { Hasil } \\
\text { pengujian }\end{array}$ & Kesimpulan \\
\hline 1 & $\begin{array}{c}\text { Tambah data, } \\
\text { jika kolom di } \\
\text { kosongkan }\end{array}$ & $\begin{array}{c}\text { Semua kolom: } \\
\text { (kosong) }\end{array}$ & $\begin{array}{c}\text { Aplikasi menolak } \\
\text { akses dan } \\
\text { menampilkan pesan } \\
\text { berupa "(kolom) }\end{array}$ & $\begin{array}{c}\text { Sesuai } \\
\text { harapan }\end{array}$ & Valid \\
& & & & \\
tidak boleh kosong" & Aplikasi menerima & Sesuai & Valid \\
\hline
\end{tabular}




\begin{tabular}{|c|c|c|c|c|c|}
\hline & jika kolom terisi & (terisi) & $\begin{array}{l}\text { akses dan menyimpan } \\
\text { data tersebut serta } \\
\text { menampilkan pesan } \\
\text { "Berhasil!, Data } \\
\text { berhasil Di simpan", }\end{array}$ & Harapan & \\
\hline 3 & $\begin{array}{l}\text { Edit data, } \\
\text { jika kolom terisi }\end{array}$ & $\begin{array}{l}\text { Salah satu } \\
\text { kolom: } \\
\text { (diubah) }\end{array}$ & $\begin{array}{l}\text { Aplikasi menerima } \\
\text { akses dan mengubah } \\
\text { data tersebut serta } \\
\text { menampilkan pesan } \\
\text { "Berhasil!, Data } \\
\text { berhasil di simpan" }\end{array}$ & $\begin{array}{c}\text { Sesuai } \\
\text { Harapan }\end{array}$ & Valid \\
\hline 4 & Hapus data, & $\begin{array}{l}\text { Menekan } \\
\text { tombol hapus } \\
\text { pada baris data } \\
\text { yang ingin } \\
\text { dihapus }\end{array}$ & $\begin{array}{l}\text { Aplikasi menerima } \\
\text { akses dan menghapus } \\
\text { data tersebut serta } \\
\text { menampilkan pesan } \\
\text { "Berhasil! Data } \\
\text { berhasil di hapus" }\end{array}$ & $\begin{array}{c}\text { Sesuai } \\
\text { Harapan }\end{array}$ & Valid \\
\hline
\end{tabular}

Sumber: Hasil Penelitian (2020)

4. Pengujian laporan penerimaan

Pengujian laporan penerimaan ini dilakukan untuk mengetahui kelayakan menu dari pencarian data pada laporan penerimaan. Hasil pengujian laporan penerimaan kas dapat dilihat pada tabel berikut.

Tabel 5. Black Box Testing Halaman Laporan Penerimaan

\begin{tabular}{cccccc}
\hline No. & $\begin{array}{c}\text { Skenario } \\
\text { pengujian }\end{array}$ & Test case & $\begin{array}{c}\text { Hasil yang } \\
\text { diharapkan }\end{array}$ & $\begin{array}{c}\text { Hasil } \\
\text { pengujian }\end{array}$ & Kesimpulan \\
\hline 1. & Jika kolom & periode awal: & Aplikasi & Sesuai harapan & Valid \\
& pencarian terisi & $(01 / 01 / 2021)$ & menampilkan laporan \\
& periode awal: & pengeluaran sesuai \\
& $(01 / 31 / 2021)$ & $\begin{array}{c}\text { dengan periode } \\
\text { pencarian }\end{array}$ & \\
& & & \\
\end{tabular}

Sumber: Hasil Penelitian (2020)

\section{KESIMPULAN}

Berdasarkan dari hasil penelitian yang dilakukan, maka beberapa kesimpulan yang dapat diambil sebagai berikut.

1. Jumlah data yang diolah sangat banyak sehingga menyebabkan pelaku pengolah data atau Admin yang mengolah penerimaan dan pengeluaran kas harus merekap satu persatu transaksi kas masuk dan kas keluar yang bersumber dari surat-surat atau bukti-bukti untuk dijadikan laporan keuangan. Pengolahan data seperti ini memerlukan tenaga, waktu yang relatif lama, kesalahan dalam pengolahan data maupun keterlambatan dalam penyajian data mengenai laporan keuangan.

2. Solusi yang dapat diterapkan oleh Davia Laundry adalah menggunakan sistem informasi akuntasi pengelolaan keuangan agar dapat mengelola penerimaan dan pengeluaran kas serta menghasilkan laporan-laporan dengan standar akuntansi.

3. Sistem informasi akuntansi pengelolaan keuangan yang dibuat dapat menyajikan pengolahan laporan keuangan sesuai dengan siklus akuntansi seperti laporan penerimaan, laporan pengeluaran, jurnal umum, buku besar, neraca saldo, laporan laba rugi dan laporan perubahan modal serta neraca.

4. Sistem informasi akuntansi pengelolaan keuangan yang dibangun ini menyediakan fasilitas sesuai dengan level aksesnya. Level akses pada sistem informasi akuntansi ini terdiri dari admin dan Pemilik. Admin dapat mengelola data akun, data pelanggan, data paket, data service dan tarif, transaksi order, transaksi pembayaran, transaksi pengeluaran, mengakses laporan penerimaan, laporan pengeluaran, jurnal umum, buku besar, neraca saldo, laporan laba rugi dan laporan perubahan modal serta neraca. Sedangkan, Pemilik dapat mengelola data pengguna, mengakses laporan penerimaan, laporan pengeluaran, jurnal umum, buku besar, neraca saldo, laporan laba rugi dan laporan perubahan modal serta neraca. 


\section{REFERENSI}

[1] Darna, N., \& Herlina, E. (2018). Memilih Metode Penelitian Yang Tepat: Bagi Penelitian Bidang Ilmu Manajemen. Jurnal Ilmu Manajemen, 5(1), 287-292. https://doi.org/10.2827/jeim.v5i1.1359

[2] Kusniawan, A., \& Sardiarinto. (2016). Perancangan Website Jasa Desain Interior Sebagai Media Pemasaran Studi Kasus: CV. Focalpoint Interior. Jurnal Evolusi, 4(2), 1-10.

[3] Sukamto, R. A., \& Shalahuddin, M. (2015). Rekayasa Perangkat Lunak Terstruktur dan Berorientasi Objek. Bandung: Informatika. 